\title{
CARACTERIZAÇÃO DE FRUTOS DE PROGÊNIES DE MEIOS-IRMÃOS DE MARACUJAZEIRO-AMARELO EM RIO BRANCO - ACRE ${ }^{1}$
}

\author{
JACSON RONDINELLIDA SILVANEGREIROS², SEBASTIÃO ELVIRO DE ARAÚJONETO ${ }^{3}$, \\ VIRGÍNIA DE SOUZA ÁLVARES², VERÍSSIMO ALVES DE LIMA ${ }^{4}$, TADÁRIO KAMEL DE OLIVEIRA²
}

RESUMO - O presente estudo teve como objetivo avaliar e caracterizar 39 progênies de meios-irmãos de maracujazeiro-amarelo para subsidiar o programa de melhoramento genético desta cultura. O delineamento experimental foi em blocos casualizados, com 39 tratamentos (39 progênies de meios-irmãos), com 2 repetições e 5 plantas por parcela. As avaliações foram feitas no segundo ano de produção. As características avaliadas foram: comprimento e diâmetro do fruto, relação comprimento/diâmetro, massa do fruto, da casca e da polpa, rendimento da polpa (arilo + sementes), espessura da casca, acidez titulável, teor de sólidos solúveis e relação sólidos solúveis /acidez titulável. Com base nas características físico-químicas dos frutos, foi possível fazer uma caracterização das 39 progênies de meios-irmãos avaliadas. Os frutos das progênies 3; 27 e 39 apresentam características desejáveis para o mercado in natura, enquanto os das progênies $9 ; 10 ; 16 ; 17 ; 32$ e 38 têm características importantes para o processamento.

Termos para indexação: Passiflora edulis; melhoramento genético; qualidade de fruto.

\section{PHYSICOCHEMICAL CHARACTERISTICS OF FRUITS OF PROGENIES OF YELLOW PASSION FRUIT TREE HALF-SIB IN RIO BRANCO - ACRE}

\begin{abstract}
The present study aimed to evaluate and to characterize 39 progenies of half-sib of yellow passion fruit tree to subsidize the program of genetic breeding of this culture. The experimental design was carried out in randomized blocks, with 39 treatments (39 progenies of half-sibs), with 2 replications and 5 plants per plot. The evaluations were done in the second year of production. The evaluated characteristics were: length and diameter of the fruit, relation of length/diameter, mass of the fruit, of the skin and of the pulp, yield of pulp (arils + seeds), thickness of the skin, titratable acidity (TA), soluble solid content (SS) and SS/TA relation. On the basis of the physicochemical characteristics of the fruits, it was possible to make a characterization of the 39 progenies of the evaluated half-sibs. The fruits of progenies 3, 27 and 39 present desirable characteristics for the in natura market, while the progenies $9,10,16,17,32$ and 38 have important characteristics for the processing.
\end{abstract}

Index Terms: Passiflora edulis; genetic breeding; fruit quality.

\section{INTRODUÇÃO}

O Brasil, centro de origem de um grande número de espécies de maracujá e maior centro de distribuição geográfica do gênero Passiflora, possui fonte de germoplasma para o melhoramento genético. Apesar disso, poucos são os relatos sobre o assunto, embora se saiba que o melhoramento pode contribuir para o aumento da produtividade da cultura. Sendo uma cultura de importância e cultivo comercial recente, a variabilidade genética do maracujazeiro ainda está por ser explorada (Meletti et al., 2000). Para desenvolver uma cultivar de maracujá, é preciso, primeiramente, conhecer, explorar e manusear a variabilidade genética disponível. Um dos pré-requisitos é a caracterização do germoplasma, recentemente iniciada no Brasil (Oliveira, 1980; Oliveira et al., 1988; Meletti et al., 1994).

O Estado do Acre apresenta uma das mais baixas produtividades e produções agrícolas do País, tendo de importar produtos alimentícios produzidos em outras regiões. O maracujá, neste Estado, possui baixa qualidade comercial, sendo um dos fatores a falta de cultivares adaptadas às condições acreanas. Um ponto positivo para a exploração do maracujazeiro no Estado é que as condições climáticas são adequadas para o desenvolvimento da planta o ano todo. Mas há necessidade de se obterem cultivares adaptadas para as condições edafoclimáticas regionais, fatores estreitamente relacionados com a eficiência de floração, frutificação e de produção do maracujazeiro.

O melhoramento do maracujazeiro (Passiflora edulis $\mathrm{f}$. flavicarpa Degener) constitui-se num campo de pesquisa promissor, devido à sua ampla variabilidade genética, ao ciclo de produção relativamente curto e ao interesse crescente pela cultura (Oliveira, 1980). A escolha dos genitores e o planejamento cuidadoso dos cruzamentos aumentam as chances do desenvolvimento de variedade superiores, pois maximiza o uso dos genes desejáveis (Borém \& Miranda, 2005).

'(Trabalho 179-07).Recebido em: 26-07-2007. Aceito para publicação em: 22-02-2008.

${ }_{2}^{2}$ esquisador da Embrapa Acre, CPAF-AC, Rio Branco - AC. CEP: 69914-220. e-mail: jacson@cpafac.embrapa.br, virginia@cpafac.embrapa.br., tadario@cpafac.embrapa,br.

${ }^{3}$ Professor da Universidade Federal de Acre, Campus da UFAC, BR-364, KM-04, Rio Branco-AC, CEP - 69915-900. e-mail: selviro2000@yahoo.com.br. ${ }^{4} \mathrm{Eng}^{\circ} \mathrm{Agr}^{\circ}$ Universidade Federal do Acre, UFAC. Rio Branco - AC. e-mail: verissimo.lima@yahoo.com.br. 
Oliveira \& Ruggiero (1998) afirmam que cada região produtora deveria desenvolver as suas variedades de maracujáamarelo, satisfazendo as exigências do consumidor, da indústria e dos produtores. Assim, a introdução de novas variedades ou acessos pode constituir-se em variedades melhoradas, quando cultivadas na nova região, ou servir como banco de genes de características especiais para serem usadas no desenvolvimento de variedades (Borém \& Miranda, 2005).

Os objetivos de um programa de melhoramento devem levar em conta o destino final do produto (Meletti \& Bruckner, 2001). O suco do maracujá-amarelo é o mais importante produto extraído do fruto, e seus componentes físico-químicos são características observadas tanto pela indústria quanto pelos consumidores do fruto in natura. Atualmente, considera-se que uma variedade desenvolvida para o mercado in natura deve apresentar frutos grandes e ovais, a fim de conseguir boa classificação comercial. Deve apresentar aceitável aparência, ser resistente ao transporte e à perda de qualidade durante o armazenamento e comercialização. Se desenvolvida para industrialização, precisa ter maior rendimento de suco, mais acidez, coloração constante e alto teor de sólidos solúveis (Oliveira et al., 1994).

O presente estudo teve o objetivo de avaliar os frutos de 39 progênies de maracujazeiro-amarelo como subsídio para o programa de melhoramento genético, caracterizando-as quanto às características físicas e físico-químicas, para o consumo in natura e/ou agroindústria.

\section{MATERIAL E MÉTODOS}

Foram avaliadas 39 progênies de meios-irmãos de maracujazeiro-amarelo cuja ascendência e procedência estão descritas na Tabela 1.

Os frutos foram obtidos da área instalada no Projeto de Assentamento Humaitá, localizada no km 22 da estrada de Porto Acre - AC, no ramal Flaviano Melo km 7.

No segundo ano de produção, de janeiro a maio de 2007, colheram-se dez frutos por parcela no estádio verde-amarelo, os quais foram identificados e transportados ao Laboratório de Ciência e Tecnologia de Alimentos - UTAL, da Universidade Federal do Acre, onde foram mensuradas as seguintes características: comprimento e diâmetro do fruto $(\mathrm{mm})$; relação comprimento/diâmetro; espessura da casca ( $\mathrm{mm})$; massa do fruto, da casca e da polpa (g); rendimento de polpa (arilo + semente) expresso em porcentagem; acidez titulável ( $\mathrm{AT}=\mathrm{g}$ de ácido cítrico por $100 \mathrm{~mL}$ de suco); teor de sólidos solúveis $\left(\mathrm{SS}={ }^{\circ}\right.$ Brix $)$ e relação SS/AT.

Nas determinações métricas, utilizou-se paquímetro digital, e as massas foram obtidas com auxílio de balança analítica. O teor de sólidos solúveis foi determinado por refratometria, utilizando-se de um refratômetro portátil, com leitura na faixa de 0 a $32^{\circ}$ Brix (AOAC, 1990). A acidez titulável foi determinada a partir de $5 \mathrm{~mL}$ de suco, do conjunto de 10 frutos, diluídos em água destilada na proporção de 5:1, usando-se indicador fenolftaleína, seguido de titulação com $\mathrm{NaOH}$ a $0,5 \mathrm{~N}$, sendo os resultados expressos em grama de ácido cítrico por $100 \mathrm{~mL}$ de suco, segundo técnica preconizada pela AOAC (1990), modificada por Araújo (2001).

O delineamento experimental foi em blocos casualizados, com 39 tratamentos (39 progênies de meios-irmãos), 2 repetições e 5 plantas totais por parcela. Para cada repetição, foram analisados 10 frutos, sendo que não foi utilizada bordadura no campo. O espaçamento utilizado foi 3,0 × 3,0 m, em espaldeira, com um fio de arame distante 2 metros do solo.

Os dados obtidos foram analisados por meio de estatística descritiva, envolvendo média, desvio-padrão e coeficiente de variação.

\section{RESULTADOS E DISCUSSÃO}

Os tratamentos 3 e 39 foram os que apresentaram comprimento do fruto acima de $80 \mathrm{~mm}$ (Tabela 2). Já na variável diâmetro do fruto, os tratamentos $1 ; 3 ; 7 ; 11 ; 13 ; 14 ; 17 ; 18 ; 21 ; 22$; $25 ; 26 ; 27 ; 31 ; 34 ; 37$ e 39 tiveram diâmetro acima de $70 \mathrm{~mm}$. O tamanho dos frutos é uma característica bastante apreciada pelo consumidor no momento da aquisição do produto, onde as progênies 3; 27 e 39 se destacaram. Comprimento e diâmetro do fruto estão relacionados com o número de sementes (Nascimento et al., 1999) e estas, ao rendimento de suco (Fortaleza et al., 2005), sendo, portanto, características interessantes tanto para frutos in natura quanto para industrialização.

A relação entre as características comprimento e diâmetro está relacionada ao formato do fruto: valor igual a 1 para frutos redondos e maiores que 1 para frutos ovalados ou oblongos (Farias et al., 2005). Para o maracujá, sempre houve preocupação em selecionar frutos ovais por serem mais comercializáveis e por apresentarem maior rendimento de suco (Manica, 1981), característica importante para os frutos destinados, principalmente, à indústria. A relação comprimento/diâmetro variou de 0,98 a 1,14 (Figura 1). Com exceção das progênies $9 ; 11$ e 32, todas as progênies avaliadas apresentaram frutos ovalados, destacando-se as progênies 23; 24; 38; 7; 31 e 39 (Tabela 2). Farias et al. (2005) observaram valores de 1,14 a 1,27 para o maracujá-amarelo.

As características físicas mais variáveis entre as progênies, em ordem decrescente, foram: massa da polpa, massa do fruto, massa da casca e espessura da casca com coeficiente de variação de $22,66 \%, 14,26 \%, 13,20 \%$ e $11,48 \%$, respectivamente (Tabela 2). Os valores estão semelhantes aos reportados na literatura. Albuquerque (2001) encontrou valores de 20,36\%, $15,11 \%, 13,24 \%, 14,78 \%, 6,06 \%$ e $5,61 \%$ para massa da polpa, massa do fruto, massa da casca, espessura da casca, comprimento e diâmetro do fruto, respectivamente. Nascimento et al. (2003), para as características de massa do fruto, espessura da casca e comprimento do fruto, obtiveram coeficientes de variação de $21,80 \%, 20,00 \%$ e $8,20 \%$, respectivamente. Esses resultados indicam, nas progênies estudadas, grande variabilidade genética quanto a estas características, o que pode ser uma vantagem no melhoramento genético do maracujazeiro-amarelo em termos de ganhos genéticos e escolha de progênies de acordo com a finalidade dos frutos. 
Dessa forma, analisando a massa do fruto, que apresentou variabilidade, os tratamentos variaram de 92,02 $\mathrm{g}$ a 179,65 g (Figura 1), com média de 124,72 g (Tabela 2). Nascimento et al. (2003) obtiveram valor médio de 161,6 $\mathrm{g}$ em 20 progênies estudadas. Machado et al. (2003) encontraram valor médio de 154,20 g, Seixas et al. (1988), 92,00 g, e Oliveira et al. (1988), 91,26 g. Frutos pesados são desejáveis para o consumo in natura, por serem mais valorizados. Dessa forma, acredita-se que as progênies 27; 39 e 3 são as mais indicadas para compor programas de melhoramento para esse tipo de mercado por apresentarem frutos com massas acima das médias encontradas na literatura $(179,65 \mathrm{~g}, 171,22 \mathrm{~g}$ e $166,80 \mathrm{~g}$, respectivamente).

Nascimento et al. (1999) consideram que as características externas do fruto constituem os parâmetros primordiais avaliados pelos consumidores e devem atender a alguns padrões para que atinjam a qualidade desejada para a comercialização. A massa do fruto é, geralmente, proporcional ao número de sementes viáveis e, no maracujá, ao rendimento de suco, uma vez que cada semente está envolta por um arilo (Fortaleza et al., 2005).

Quanto à massa da polpa, característica com maior coeficiente de variação entre as progênies, os tratamentos variaram de 29,15 g a 70,05 g (Figura 1), com média de 44,46 g (Tabela 2). As progênies 14; 3; 27; 13 e 39 apresentaram os maiores valores médios, $70,05 \mathrm{~g}, 66,25 \mathrm{~g}, 65,70 \mathrm{~g}, 56,70 \mathrm{~g}$ e $54,90 \mathrm{~g}$, respectivamente (Tabela 2 ).

Entretanto, foi realizado o cálculo da percentagem de polpa em relação à massa do fruto para melhor visualização do rendimento de suco, visando à comercialização para indústrias, embora a pesagem tenha sido realizada com as sementes. Observa-se que as progênies 14;26; 24; 3 e 7 tiveram os maiores rendimentos de polpa dentre as progênies avaliadas, com 45,83\%, $42,39 \%, 40,73 \%, 39,72 \%$ e $39,60 \%$, respectivamente, indicandoas como progênies promissoras tanto para a industrialização como para o consumo in natura.

Para a massa da casca, $61 \%$ das progênies avaliadas exibiram frutos com médias inferiores a 80,37 $\mathrm{g}$ (Tabela 2), com variação de 56,58 g a 116,32 g (Figura 1). Os tratamentos 8; 9; 10; $16 ; 24 ; 30$ e 38 apresentaram massa da casca inferior a 70,0 g. O valor de massa da casca elevado é uma característica indesejável por não contribuir para o rendimento do suco, principalmente para frutos destinados ao processamento industrial.

Da mesma forma, maior espessura da casca relacionase com menor rendimento em suco (Oliveira et al., 1988). As menores médias obtidas foram observadas nos tratamentos 10 ; $16 ; 17 ; 24$ e 31, sendo que os valores máximo e mínimo foram de $9,07 \mathrm{~mm}$ e de 4,66 mm, respectivamente (Figura 1), com média de $6,43 \mathrm{~mm}$ (Tabela 2). Nascimento (1996) cita que, tanto a indústria de suco concentrado como o mercado da fruta in natura, considera a espessura da casca um fator relevante para a classificação do fruto, por ser inversamente proporcional ao rendimento de suco. Nascimento et al. (1999) consideram satisfatórios o padrão de espessura da casca menor que $5 \mathrm{~mm}$, para ambos os mercados. De acordo com esta observação, as progênies 10 e 16 são as mais adequadas para uma seleção com esta característica.
Os resultados encontrados para as características físicoquímicas estão apresentados na Tabela 2. Verifica-se que a variação entre as progênies foi de 5,19\%, 10,86\% e 13,89\%, para SS, AT e relação SS/AT, respectivamente. Nascimento et al. (2003) encontraram valores semelhantes com uma variação de $6,4 \%$ para SS e de $19 \%$ para AT.

Tanto para a indústria quanto para o mercado de frutos in natura, o teor de sólidos solúveis (SS) deve ser elevado. Para a indústria, por exemplo, quanto maior o valor de SS dos frutos, menor a quantidade de frutos utilizada para a concentração do suco. Os maiores teores observados foram nos tratamentos 10; 17; 38; 9 e 32, cujos valores estão acima da média (Tabela 2), destacando-os como genótipos promissores para pesquisas de melhoramento. $\mathrm{O}$ valor médio para SS foi de $15,72^{\circ}$ Brix, com valor máximo de 17,30 para o tratamento 10 e mínimo de 13,31 para o tratamento 26 (Figura 1). Os tratamentos 26 e 27 tiveram os menores valores de SS abaixo de $14^{\circ}$ Brix. No entanto, os tratamentos estão em conformidade com a legislação, que preconiza o mínimo para SS de $11,00^{\circ}$ Brix (Brasil, 2003). Oliveira et al. (1999) relatam que os sólidos solúveis, medidos por refratometria, são usados como índice de açúcares totais em frutos. São constituídos por compostos solúveis em água, tais como açúcares, ácidos, vitamina $\mathrm{C}$ e algumas pectinas.

$\mathrm{Na}$ literatura, os valores de SS obtidos para o maracujá variam consideravelmente. Farias et al. (2005) encontraram valores médios de $11,46^{\circ}$ Brix, Chen et al. (1991) relatam valores médios de $15,5^{\circ}$ Brix, Nascimento et al. (2003) citam valores de $16,2^{\circ}$ Brix e Gamarra Rojas \& Medina (1996), de 16,8 Brix. De acordo com Nascimento et al. (2003), as diferenças nos teores de SS reportadas nos trabalhos com maracujá-amarelo podem ser conseqüência da variabilidade inerente à forma flavicarpa.

Nascimento et al. (1999) consideram que as variedades destinadas à industrialização devem apresentar, além de alto rendimento de suco, sólidos solúveis em torno de $16^{\circ}$ Brix e coloração da casca uniforme. De acordo com esta observação, as progênies $6 ; 9 ; 10 ; 15 ; 16 ; 17 ; 18 ; 20 ; 24 ; 32 ; 33 ; 34$ e 38 podem compor um programa de melhoramento genético visando ao mercado de frutos para a indústria.

A acidez do fruto é uma característica também importante para a indústria, pois desfavorece a manifestação de microrganismos e, conseqüentemente, confere maior tempo de conservação do produto. Por outro lado, a acidez proporciona um sabor não muito doce, o que não agrada aos consumidores de frutas in natura. Tendo em vista as modalidades de mercado a que se destinam, os frutos apresentaram características de AT adequadas tanto para frutos in natura quanto para industrialização.

O valor médio da acidez titulável (AT) foi de 3,98 g ácido cítrico $100 \mathrm{~mL}^{-1}$ (Tabela 2), com valor máximo de 4,82 e mínimo de $3,22 \mathrm{~g}$ ácido cítrico. $100 \mathrm{~mL}^{-1}$ (Figura 1). Nascimento et al. (2003) obtiveram valor médio para AT de $3,40 \%$, e valores máximo e mínimo de 4,49\% e 2,29\%, respectivamente, no estudo da seleção de progênies de maracujazeiro-amarelo. O Ministério da Agricultura no Brasil (Brasil, 2003) estabelece como padrão o valor mínimo de 2,5 para AT para suco de maracujá. Dessa forma, 
todos os tratamentos se encontram de acordo com a legislação brasileira.

Entretanto, SS e AT devem ser analisados em conjunto, pois o sabor dos frutos é avaliado pela relação SS/AT e deve-se ao balanço de ácidos e açúcares (Chitarra \& Chitarra, 2005). A relação SS/AT oscilou de 3,26 a 5,18 (Figura 1), com média de 4,01 (Tabela 2). Esses resultados foram semelhantes aos relatados por Pinheiro et al. (2006), que analisaram sucos integrais de abacaxi, caju e maracujá, cuja a relação SS/AT do suco de maracujá foi de 4,40. Nascimento et al. (2003) citam que o teor de açúcar e a acidez dos frutos podem sofrer variação em decorrência de fatores ambientais, práticas de cultivo, qualidade de luz solar, temperatura, como também do tipo e dosagens de fertilizantes, portanto com reflexos diretos na relação SS/AT. Segundo esses autores a acidez é um ponto decisivo quando alcança valores elevados, acarretando redução nos valores de SS/AT, cuja relação está intimamente ligada ao teor de açúcar e ácidos no fruto. Isso pode ser confirmado nas progênies 13; 29 e 30, por exemplo, que possuíam AT elevadas. Já nas progênies 6; 16; 20 e 32, que tiveram menores valores de AT, o valor da relação SS/ AT foi elevado. O maior valor nesta relação foi obtido na progênie 32, que possuía elevado valor de SS e baixo de AT; neste caso, predominou o teor de açúcar em detrimento ao teor de ácidos.

TABELA 1 - Ascendência e procedência de progênies de meios-irmãos de maracujazeiro -amarelo avaliados durante o segundo ciclo de produção, Rio Branco - AC.

\begin{tabular}{ccc}
\hline Tratamentos & Ascendência & Procedência \\
\hline 1 & IAC275 & ViçosaMG \\
2 & Viçosa 1 ViçasaMG \\
3 & Viçosa 6 & ViçosaMG \\
4 & Viçosa 9 & ViçosaMG \\
5 & Viçosa 10 & ViçosaMG \\
6 & Vicosa 11 & ViçosaMG \\
7 & Viçosa 13 & ViçosaMG \\
8 & Viçosa 23 & ViçosaMG \\
9 & Viçosa 24 & ViçosaMG \\
10 & Viçosa 25 & ViçosaMG \\
11 & Viçosa 26 & ViçosaMG \\
12 & Viçosa 85 & ViçosaMG \\
13 & BORD88 & ViçosaMG \\
14 & Viçosa 86 & ViçosaMG \\
15 & 59 A & UENFRJ \\
16 & $60 \mathrm{~A}$ & UENFRJ \\
17 & $64 \mathrm{~A}$ & UENF-RJ \\
18 & $64 \mathrm{~B}$ & UENFRJ \\
19 & $64 \mathrm{C}$ & UENFRJ \\
20 & $65 \mathrm{C}$ & UENFRJ \\
21 & $66 \mathrm{~A}$ & UENFRJ \\
22 & $68 \mathrm{C}$ & UENFRJ \\
23 & $76 \mathrm{C}$ & UENFRJ \\
24 & $78 \mathrm{C}$ & UENFRJ \\
25 & $123 \mathrm{~B}$ & UENFRJ \\
26 & BLI 01 & BrasiléiaAC \\
27 & RBC01 & Rio BranceAC \\
28 & $2 \mathrm{~A}$ & UENFRJ \\
29 & $11 \mathrm{~B}$ & UENFRJ \\
30 & $11 \mathrm{C}$ & UENFRJ \\
31 & $17 \mathrm{C}$ & UENFRJ \\
32 & $21 \mathrm{~A}$ & UENFRJ \\
33 & $30 \mathrm{C}$ & UENFRJ \\
34 & $37 \mathrm{C}$ & UENFRJ \\
35 & $39 \mathrm{~A}$ & UENFRJ \\
36 & $54 \mathrm{~A}$ & UENFRJ \\
37 & $55 \mathrm{~A}$ & UENFRJ \\
38 & $55 \mathrm{~B}$ & UENFRJ \\
39 & $55 \mathrm{C}$ & UENFRJ \\
\hline
\end{tabular}

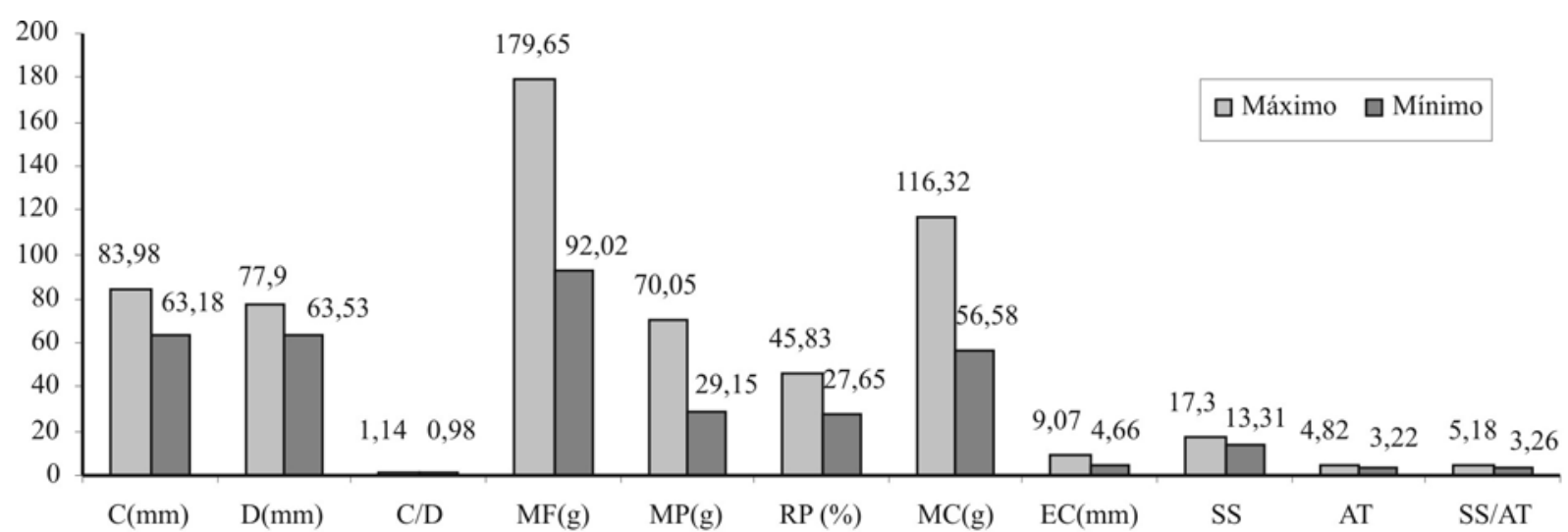

FIGURA 1 - Valores máximos e mínimos das características analisadas em maracujazeiro-amarelo. 
TABELA 2 - Valores médios das características físicas e físico-químicas, média geral, desvio- padrão e coeficiente de variação dos frutos de maracujazeiro-amarelo.

\begin{tabular}{|c|c|c|c|c|c|c|c|c|c|c|c|}
\hline Tratamentos & $\mathbf{C}(\mathrm{mm})$ & $\mathbf{D}(\mathrm{mm})$ & C/D & MF $(g)$ & $\mathbf{M P}(\mathrm{g})$ & RP (\%) & MC $(g)$ & $\mathbf{E C}(\mathrm{mm})$ & SS & AT & SS/AT \\
\hline 1 & 74,37 & 70,30 & 1,06 & 127,87 & 46,90 & 36,70 & 80,97 & 6,90 & 15,67 & 3,97 & 3,99 \\
\hline 2 & 74,87 & 69,16 & 1,08 & 127,12 & 44,78 & 35,23 & 82,34 & 7,47 & 15,09 & 3,73 & 4,09 \\
\hline 3 & 83,96 & 76,37 & 1,10 & 166,80 & 66,25 & 39,72 & 100,55 & 6,10 & 15,13 & 4,37 & 3,50 \\
\hline 4 & 65,17 & 64,33 & 1,01 & 116,05 & 43,55 & 37,53 & 72,50 & 5,83 & 15,74 & 4,49 & 3,52 \\
\hline 5 & 72,65 & 69,33 & 1,05 & 123,12 & 47,20 & 38,34 & 75,92 & 6,32 & 15,39 & 3,70 & 4,17 \\
\hline 6 & 73,03 & 68,08 & 1,07 & 122,95 & 45,85 & 37,29 & 77,10 & 6,28 & 16,21 & 3,55 & 4,59 \\
\hline 7 & 79,20 & 70,85 & 1,12 & 129,59 & 51,32 & 39,60 & 78,26 & 5,56 & 15,89 & 4,25 & 3,76 \\
\hline 8 & 70,80 & 66,78 & 1,06 & 106,20 & 37,00 & 34,84 & 69,20 & 6,19 & 15,88 & 3,94 & 4,10 \\
\hline 9 & 63,18 & 63,79 & 0,99 & 93,92 & 29,82 & 31,75 & 64,11 & 6,25 & 16,69 & 3,88 & 4,33 \\
\hline 10 & 69,52 & 65,42 & 1,06 & 107,99 & 41,90 & 38,80 & 66,09 & 4,68 & 17,30 & 3,88 & 4,50 \\
\hline 11 & 70,37 & 71,25 & 0,99 & 128,30 & 49,65 & 38,70 & 78,65 & 5,86 & 15,65 & 3,97 & 3,95 \\
\hline 12 & 73,19 & 66,57 & 1,10 & 112,30 & 37,11 & 33,04 & 75,20 & 6,51 & 15,45 & 3,93 & 3,94 \\
\hline 13 & 78,18 & 74,94 & 1,04 & 154,85 & 56,70 & 36,62 & 98,15 & 7,29 & 14,94 & 4,41 & 3,40 \\
\hline 14 & 76,62 & 72,39 & 1,06 & 152,85 & 70,05 & 45,83 & 82,80 & 6,19 & 15,49 & 4,06 & 4,01 \\
\hline 15 & 72,36 & 68,66 & 1,05 & 119,81 & 45,38 & 37,88 & 74,43 & 5,90 & 16,05 & 4,05 & 4,00 \\
\hline 16 & 67,88 & 63,53 & 1,07 & 92,02 & 35,45 & 38,52 & 56,58 & 4,66 & 16,64 & 3,62 & 4,64 \\
\hline 17 & 75,35 & 73,51 & 1,02 & 126,49 & 43,60 & 34,47 & 82,89 & 5,04 & 16,71 & 3,88 & 4,38 \\
\hline 18 & 73,45 & 70,03 & 1,05 & 116,24 & 34,49 & 29,67 & 81,75 & 6,82 & 16,40 & 3,91 & 4,22 \\
\hline 19 & 72,25 & 66,51 & 1,09 & 108,76 & 37,75 & 34,71 & 71,11 & 6,34 & 15,85 & 4,05 & 3,93 \\
\hline 20 & 71,41 & 69,98 & 1,02 & 114,40 & 39,15 & 34,22 & 75,25 & 5,64 & 16,45 & 3,55 & 4,64 \\
\hline 21 & 78,03 & 73,07 & 1,07 & 133,43 & 41,54 & 31,13 & 91,89 & 6,71 & 15,59 & 4,17 & 3,82 \\
\hline 22 & 76,17 & 72,07 & 1,06 & 134,65 & 48,45 & 35,98 & 86,20 & 6,72 & 15,17 & 3,89 & 3,92 \\
\hline 23 & 78,33 & 68,87 & 1,14 & 120,86 & 45,91 & 37,99 & 74,95 & 5,56 & 15,53 & 3,68 & 4,22 \\
\hline 24 & 76,17 & 67,31 & 1,13 & 117,49 & 47,85 & 40,73 & 69,64 & 5,34 & 16,12 & 4,14 & 3,94 \\
\hline 25 & 76,84 & 71,47 & 1,07 & 150,72 & 41,67 & 27,65 & 109,05 & 8,13 & 15,80 & 3,56 & 4,44 \\
\hline 26 & 73,79 & 70,13 & 1,05 & 129,17 & 54,75 & 42,39 & 78,59 & 6,95 & 13,31 & 3,99 & 3,35 \\
\hline 27 & 77,77 & 77,90 & 1,00 & 179,65 & 65,70 & 36,57 & 113,95 & 9,07 & 13,98 & 4,22 & 3,44 \\
\hline 28 & 67,19 & 65,83 & 1,02 & 102,95 & 32,65 & 31,71 & 70,30 & 9,07 & 15,54 & 3,69 & 4,26 \\
\hline 29 & 70,22 & 67,50 & 1,04 & 126,11 & 47,71 & 37,83 & 78,40 & 7,28 & 15,67 & 4,82 & 3,26 \\
\hline 30 & 65,67 & 65,23 & 1,01 & 102,33 & 39,78 & 38,87 & 62,56 & 6,24 & 15,19 & 4,41 & 3,45 \\
\hline 31 & 78,22 & 70,65 & 1,11 & 136,60 & 51,10 & 37,41 & 85,50 & 5,38 & 15,63 & 4,05 & 3,86 \\
\hline 32 & 67,18 & 68,71 & 0,98 & 109,21 & 37,40 & 34,25 & 71,81 & 6,51 & 16,68 & 3,22 & 5,18 \\
\hline 33 & 67,50 & 65,85 & 1,02 & 104,70 & 29,15 & 27,84 & 75,55 & 6,10 & 16,15 & 4,14 & 3,92 \\
\hline 34 & 74,61 & 72,18 & 1,03 & 132,25 & 37,20 & 28,13 & 95,05 & 6,41 & 16,33 & 3,88 & 4,25 \\
\hline 35 & 71,16 & 67,78 & 1,05 & 117,15 & 36,80 & 31,41 & 80,35 & 6,56 & 15,73 & 4,08 & 4,02 \\
\hline 36 & 74,17 & 69,66 & 1,06 & 133,25 & 42,65 & 32,01 & 90,60 & 7,28 & 15,32 & 4,15 & 3,71 \\
\hline 37 & 75,18 & 70,63 & 1,06 & 113,64 & 35,96 & 31,64 & 77,68 & 6,79 & 14,94 & 3,90 & 3,91 \\
\hline 38 & 71,74 & 64,11 & 1,12 & 101,19 & 38,81 & 38,35 & 62,38 & 5,86 & 16,70 & 3,90 & 4,29 \\
\hline 39 & 83,98 & 75,54 & 1,11 & 171,22 & 54,90 & 32,06 & 116,32 & 7,10 & 14,96 & 4,07 & 3,68 \\
\hline Média Geral & 73,38 & 69,39 & 1,06 & 124,72 & 44,46 & $\mathbf{3 5 , 5 7}$ & $\mathbf{8 0 , 3 7}$ & 6,43 & 15,72 & 3,98 & 4,01 \\
\hline $\begin{array}{l}\text { Desvio- } \\
\text { Padrão }\end{array}$ & 4,73 & 3,53 & 0,04 & 20,26 & 9,44 & 4,07 & 13,50 & 0,97 & 0,76 & $\mathbf{0 , 3 0}$ & $\mathbf{0 , 4 1}$ \\
\hline CV $(\%)$ & 5,62 & 4,75 & $\mathbf{8 , 8 7}$ & 14,26 & 22,66 & $\mathbf{8 , 8 7}$ & 13,20 & 11,48 & 5,19 & 10,86 & 13,89 \\
\hline
\end{tabular}

$\mathrm{C}=$ comprimento do fruto; $\mathrm{D}=$ diâmetro equatorial do fruto; $\mathrm{C} / \mathrm{D}=$ relação comprimento/diâmetro; $\mathrm{MF}=$ massa do fruto; $\mathrm{MP}=$ massa da polpa; $\mathrm{RP}=$ rendimento de polpa; $\mathrm{MC}=$ massa da casca; $\mathrm{EC}=$ espessura de casca; $\mathrm{SS}=$ teor de sólidos solúveis; $\mathrm{AT}=$ acidez titulável $\left(\mathrm{g}\right.$ ác.cítrico.100 $\left.\mathrm{mL}^{-1}\right)$ e $\mathrm{SS} / \mathrm{AT}$ = relação de solúveis/acidez titulável. 


\section{CONCLUSÕES}

1-Nas progênies avaliadas, obtiveram-se características desejáveis tanto para o mercado in natura como para a indústria, assim como superioridade de alguns acessos para futuros trabalhos de melhoramento.

2-Os frutos das progênies 3; 27 e 39 apresentam características desejáveis para o mercado in natura, enquanto os das progênies $9 ; 10 ; 16 ; 17 ; 32$ e 38 têm características importantes para a agroindústria.

\section{REFERÊNCIAS}

ALBUQUERQUE, A. S. Seleção de genitores e híbridos em maracujazeiro (Passiflora edulis Sims). 2001. 90f. Tese (Doutorado em genética e melhoramento) - Departamento de Genética e Melhoramento, Universidade Federal de Viçosa, 2001.

ARAÚJO, R. da C. Produção, qualidade de frutos e teores foliares de nutrientes no maracujazeiro amarelo em resposta à nutrição potássica. 2001. 103f. Tese (Doutorado em Fitotecnia) Departamento de Fitotecnia, Universidade Federal de Viçosa, Viçosa, 2001.

AOAC - ASSOCIAÇÃO OF OFFICIAL ANALITICAL CHEMISTS. Official Methods Analysis the Association of Official Analitical Chemists. 15th ed. Arlington, 1990. p. 6851213.

BORÉM, A.; MIRANDA, G. V. Melhoramento de plantas. 4. ed. Viçosa: Editora UFV, 2005. p. 525

BRASIL. Ministério da Agricultura e do Abastecimento. Instrução Normativa $N^{o} 12$ de 4 de Setembro de 2003. Diário Oficial, Brasília, 2003. Seção1, p.72-76.

CHEN, C. S.; CARTER, R. D.; BARROS, S. M.; NAGY, S.; HERNANDEZ, E. Evaluation of citrus processing system for passion fruit juice concentration. Proceeding Florida State Horticultural Society, Winter Haven, v. 104, n. 104, p. 51-54, 1991.

CHITARRA, M. I. F.; CHITARRA, A. B. Pós-colheita de frutas e hortaliças: fisiologia e manuseio. 2. ed. Lavras: UFLA, 2005. p. 785 .

FARIAS, M. A. A.; FARIA, G. A.; CUNHA, M. A. P.; PEIXOTO, C. P.; SOUSA, J. S. Caracterização física e química de frutos de maracujá amarelo de ciclos de seleção massal estratificada e de populações regionais. Magistra, Cruz das Almas, v. 17, n. 2, p. 83-87, 2005

FORTALEZA, J. M.; PEIXOTO, J. R.; JUNQUEIRA, N. T. V.; OLIVEIRA, A. T.; RANGEL, L. E. P. Características físicas e químicas em nove genótipos de maracujá-azedo cultivado sob três níveis de adubação potássica. Revista Brasileira de Fruticultura, Jaboticabal, v. 27, n. 1, p. 124-127, 2005.

GAMARRA ROJAS, G.; MEDINA, V. M. Mudanças bioquímicas do suco de maracujá-amarelo em função da idade do fruto. Revista Brasileira de Fruticultura, Cruz da Almas, v. 18, n. 1, p. 75-83, 1996.

MACHADO, S. S.; CARDOSO, R. L.; MATSUURA, F. C. A. U.; FOLEGATTI, M. I. S. Caracterização física e físico-química de frutos de maracujá amarelo provenientes da região de Jaguaquara - Bahia. Magistra, Cruz das Almas, v. 15, n. 2, p. 229-233, 2003. MANICA, I. Fruticultura Tropical. Maracujá. São Paulo, SP. Ceres, 1981.p. 19-32.

MELETTI, L. M. M.; BRUCKNER, C. H. Melhoramento genético. In: BRUCKNER, C. H.; PICANÇO, M. C. Maracujá: tecnologia de produção, pós, colheita, agroindústria, mercado. Porto Alegre: Cinco continentes, 2001. p. 345-385.

MELETTI, L. M. M.; SOARES-ESCOTT, M. D.; BERNACCI, L. C.; MARTINS, F. P.; PINTO-MAGLIO, C.A.F. Caracterização agronômica e seleção de germoplasma de maracujá (Passiflora spp.). In: CONGRESSO BRASILEIRO DE FRUTICULTURA, 13., 1994, Salvador. Anais... Cruz das Almas: Sociedade Brasileira de Fruticultura, 1994. p. 821-822.

MELETTI, L. M. M.; SANTOS, R.R. dos; MINAMI, K. Melhoramento do maracujazeiro-amarelo: obtenção do cultivar 'composto IAC-27'. Scientia Agricola, Piracicaba, v. 57, n. 3, p. 491-498, 2000.

NASCIMENTO, T.B. do. Qualidade do maracujá-amarelo produzido em diferentes épocas no sul de Minas Gerais. 1996. 56 f. Dissertação (Mestrado) - Universidade Federal de Lavras, Lavras, 1996.

NASCIMENTO, T. B.; RAMOS, J. D.; MENEZES, J. B. Características físicas do maracujá-amarelo produzido em diferentes épocas. Pesquisa Agropecuária Brasileira, Brasília, v. 34, n. 12, p. 2353-2358, 1999.

NASCIMENTO, W. M. O.; TOMÉ, A. T.; OLIVEIRA, M. S. P.; MÜLLER, C. H.; CARVALHO, J. E. U. Seleção de progênies de maracujazeiro-amarelo (Passiflora edulis f. flavicarpa) quanto à qualidade de frutos. Revista Brasileira de Fruticultura, Jaboticabal, v.25, n.1, p. 186-188, 2003.

OLIVEIRA, J.C. de. Melhoramento genético de Passiflora edulis f. flavicarpa visando ao aumento de produtividade. 1980. 133f. Dissertação (Mestrado) - Faculdade de Ciências Agrárias e Veterinária, Universidade estadual Paulista, Jaboticabal, 1980.

OLIVEIRA, J.C. FERREIRA, F.R.; RUGGIERO, C.; NAKAMURA, K. Caracterização e avaliação de germoplasma de Passiflora 
edulis. In: CONGRESSO BRASILEIRO DE FRUTICULTURA, 9., 1988, Campinas. Anais... Campinas: Sociedade Brasileira de Fruticultura, 1988. p. 591-595.

OLIVEIRA, J.C.; NAKAMURA, K.; MAURO, A.O.; CENTURION, M.A.P.C. Aspectos gerais do melhoramento do maracujazeiro. In: SÃO JOSÉ, A.R. Maracujá: produção e mercado. Vitória da Conquista: DFZ/UESB, 1994. p. 27-37.

OLIVEIRA, M.E.B. de; BASTOS, M.S.R.; FEITOSA, T. Avaliação de parâmetros de qualidade físico-química de polpa congelada de acerola, cajá e caju. Ciências e Tecnologia de Alimentos, Campinas, v. 19, n. 3, p. 326-332, 1999.

OLIVEIRA, J. C.; RUGGIERO, C. Aspecto sobre o melhoramento do maracujazeiro amarelo. In: SIMPÓSIO BRASILEIRO SOBRE A CULTURA DO MARACUJAZEIRO, 5., 1998, Jaboticabal. Anais... Jaboticabal: Funep, 1998. p. 291-310.
PINHEIRO, M. A.; FERNANDES, G. A.; FAI, C. E. A.; PRADO, M. G.; SOUSA, M. H. P.; MAIA, A. G. Avaliação química, físicoquimica e microbiológica de sucos de frutas integrais: abacaxi, caju e maracujá. Ciência e Tecnologia de Alimentos, Campinas, v. 26, n. 1, p. 98-103, 2006.

SEIXAS, L.F.Z.; OLIVEIRA, J.C. de; TIHOHOD, D.; RUGGIERO, C. Comportamento de Passiflora macrocarpa como porta-enxerto para Passiflora edulis Sims f. flavicarpa Deg., cultivado em local com histórico de morte prematura de plantas e nematóides do maracujazeiro. In: CONGRESSO BRASILEIRO DE FRUTICULTURA, 9., 1988, Campinas, SP. Anais... Campinas: Sociedade Brasileira de Fruticultura, 1988. p.597-601. 